ROLE OF CAPSAICIN- AND HEAT-SENSITIVE AFFERENTS

IN STIMULATION OF ACUPOINT-INDUCED PAIN AND ANALGESIA IN HUMANS

Lei, Jing

2017-09-01

Lei , J , Ye , G , Wu , J-T, Pertovaara , A \& You , H-J 2017 , ' ROLE OF CAPSAICIN- AND HEAT-SENSITIVE AFFERENTS IN STIMULATION OF ACUPOINT-INDUCED PAIN AND ANALGESIA IN HUMANS ' , Neuroscience , vol. 358 , pp. 325-335 . https://doi.org/10.1016/j.neuroscience.2017.06.

http://hdl.handle.net/10138/297940

https://doi.org/10.1016/j.neuroscience.2017.06.051

publishedVersion

Downloaded from Helda, University of Helsinki institutional repository.

This is an electronic reprint of the original article.

This reprint may differ from the original in pagination and typographic detail.

Please cite the original version. 


\section{ROLE OF CAPSAICIN- AND HEAT-SENSITIVE AFFERENTS IN STIMULATION OF ACUPOINT-INDUCED PAIN AND ANALGESIA IN HUMANS}

\author{
JING LEI, ${ }^{\mathrm{a}, \mathrm{d}}$ GANG YE, ${ }^{\mathrm{b}}$ JIANG-TAO WU, ${ }^{\mathrm{c}}$ \\ ANTTI PERTOVAARA ${ }^{d}$ AND HAO-JUN YOU ${ }^{\mathrm{a} *}$ \\ ${ }^{\text {a }}$ Center for Biomedical Research on Pain (CBRP), College \\ of Medicine, Xi'an Jiaotong University, Xi'an 710061, PR China \\ ${ }^{\mathrm{b}}$ Department of Rehabilitation Medicine, Tongji Hospital Affiliated \\ to Shanghai Tongji University, Shanghai 200065, PR China \\ ${ }^{\mathrm{c}}$ MOE Key Laboratory of Thermo-Fluid Science and \\ Engineering, School of Energy and Power Engineering, \\ Xi'an JiaoTong University, Xi'an 710049, PR China \\ d Institute of Biomedicine/Physiology, University of Helsinki, $P O B$ \\ 63, Helsinki 00014, Finland
}

\begin{abstract}
We investigated role of capsaicin-sensitive afferents within and without the areas of Zusanli (ST36)/Shangjuxu (ST37) acupoints along the stomach (ST) meridian in the perception and modulation of pain assessed by visual analog scale of pain and its distribution rated by subjects, pressure pain threshold (PPT), and heat pain threshold (HPT) in humans. Compared with the treatment of nonacupoint area, capsaicin $(100 \mu \mathrm{g} / 50 \mu \mathrm{l})$ administered into either ST36 or ST37 acupoint caused the strongest pain intensity and the most extensive pain distribution, followed by rapid onset, bilateral, long-lasting secondary mechanical hyperalgesia and slower onset secondary heat hypoalgesia (1 day after the capsaicin treatment). Between treatments of different acupoints, capsaicin administrated into the ST36 acupoint exhibited the stronger pain intensity and more widespread pain distribution compared with the treatment of ST37 acupoint. A period of 30 - to $45-\mathrm{min}$, but not 15 $\min , 43^{\circ} \mathrm{C}$ heating-needle stimulation applied to the ST36 acupoint significantly enhanced the HPT, and had no effect on PPT. Upon trapezius muscle pain elicited by the i.m. injection of $5.8 \%$ saline, pre-emptive treatment of the contralateral ST36 acupoint with $43^{\circ} \mathrm{C}$ heating-needle stimulation alleviated the ongoing muscle pain, reduced painful area, and reversed the decrease in HPT. It is suggested that (1) pain elicited from the acupoint and non-acupoint areas differs significantly, which are supposed to be dependent on the different distributions and contributions of capsaicin-sensitive afferents. (2) Non-painful heat stimulation is a valid approach in prevention of ongoing muscle pain with associated post-effects of peripheral and central
\end{abstract}

\footnotetext{
${ }^{*}$ Corresponding author. Address: Center for Biomedical Research on Pain (CBRP), College of Medicine, Xi'an Jiaotong University, 76\# Yanta West Road, Xi'an, Shaanxi 710061, PR China.

E-mail address: yhi@mail.xjtu.edu.cn (H.-J. You).

Abbreviations: DNIC, diffuse noxious inhibitory controls; HNS, heatingneedle stimulation; HPT, heat pain threshold; HT, hypertonic; PPT, pressure pain threshold; ST, stomach; VAS, visual analog scale.
}

sensitization. (c) 2017 IBRO. Published by Elsevier Ltd. All rights reserved.

Key words: acupoint, capsaicin, muscle pain, endogenous controls of pain, hyperalgesia, hypoalgesia.

\section{INTRODUCTION}

As a warning signal, pain is complex sensory and emotional experience elicited by noxious stimulation in physiological condition as well as innocuous stimulation in pathological state (Hardy et al., 1952). However, pain, in particular chronic pathological pain, may seriously influence the quality of life and it brings heavy commitment to patients and society. Thus, effective therapy involving various pharmacological and non-pharmacological interferences in treating pain has extensively been explored in both basic research area and clinical trails.

It is generally accepted that pain sensation is subject not only to modulation during its ascending transmission from the periphery to the cerebral cortex, but also to spinal segmental modulation and descending control from supraspinal structures (Melzack and Wall, 1965; Fields et al., 2006). With respect to endogenous descending modulation, it was reported that unilateral nociceptive stimulation of deep somatic structures, i.e. muscle, causes local pain associated with secondary mechanical hyperalgesia and heat hypoalgesia in bilateral sites, which are specifically governed by descending facilitation and inhibition, respectively (You et al., 2010; Lei et al., 2011; Lei and You, 2012, 2013). Furthermore, recent developments have heightened the need and importance for recruiting $\mathrm{C}$-afferents in initiating endogenous modulation of pain due to the fact that the descending modulation: facilitation and inhibition, is physiologically inactive and 'silent' (You et al., 2010, 2013; Lei et al., 2011). As not all thermally sensitive $C$ fibers are nociceptive (Besson and Chaouch, 1987), it actually brings hope to effectively initiate the endogenous descending inhibition of pain by means of heating stimulation at a non-painful temperature, i.e. $43^{\circ} \mathrm{C}$ (You et al., 2014).

Traditional Chinese acupuncture has a history of over 3000 years. It is a treatment procedure in which silver or steel needles are specifically inserted into different acupoints throughout the body. Numerous studies reported that following the application of acupuncture, 
gradually developed and long-lasting analgesia can be observed (Chiang et al., 1973; Pomeranz and Chiu, 1976; Han et al., 1984; Cui et al., 2005; You et al., 2006). Despite the analgesia elicited by acupuncture, there are still much debate related to effects of treatment of acupoint and its mechanisms. For instance, it is yet unclear what are the differences between analgesic therapy of acupoint and diffuse noxious inhibitory controls (DNIC) of pain (Le Bars et al., 1979). From mechanism perspective, it has been initially supposed that excitement of thick afferents, in particular $A \beta$ fibers, by electroacupuncture is capable of inducing analgesia (Levine et al., 1976; Kawakita and Funakoshi, 1982; Lu, 1983; Leung et al., 2005). Given the evidence, however, showing that the acupuncture-induced analgesic effects are dependent on the intensity of stimulation, and are significantly decreased after the blockade of peripheral $\mathrm{C}$ afferents (Zhu et al., 1990; Wang et al., 1997), the major involvement of unmyelinated afferents within deep tissue in stimulation of acupoint- or acupuncture-induced analgesia should be considered (Radhakrishnan and Sluka, 2005).

The present study was aimed to explore: (1) whether treatment of acupoint and non-acupoint differ in eliciting pain and triggering descending control of pain, and (2) potential effects of non-painful heat stimulation in control of pain. Employing capsaicin and non-painful heatingneedle stimulation at the temperature of $43^{\circ} \mathrm{C}$, we found that capsaicin-sensitive fibers probably distributed differently within the acupoint and non-acupoint areas. Non-painful $43^{\circ} \mathrm{C}$ heat stimulation is proved to be a valid approach in prevention of pain associated with post-effects of peripheral and central sensitization in human subjects.

\section{EXPERIMENTAL PROCEDURES}

\section{Subjects}

Fifty male volunteers participated in the current study, mean age 23.4 years, range $18-43$ years. None had signs of peripheral neuropathy or central nervous system disorders. None had either chronic pain or under any medication regimes. They were informed about the experimental procedures and signed a consent form which conducted in accordance with the Declaration of Helsinki. The experiments were approved by Ethics Committee of Xi'an Jiaotong University. The trials were performed in a quiet room with a temperature of 22 $23^{\circ} \mathrm{C}$.

\section{Treatment with capsaicin/Tween 80 at ST36/37, non- ST36/37, and non-ST35/36 sites}

Capsaicin $100 \mu \mathrm{g} / 50 \mu \mathrm{l}$ (vehicle: $8.3 \% \mathrm{vol} / \mathrm{vol}$ Tween 80 in $0.9 \%$ saline) and vehicle $50 \mu \mathrm{l}$ were injected intramuscularly with a $30-G$ needle, respectively. The injection site was on the unilateral leg at ST36 (Zusanli)/ ST37 (Shangjuxu) acupoints and non-acupoint area. ST36 located four-finger breadth below the lower margin of the patella and one-finger breadth laterally from the anterior crest of the tibia on leg. ST37 located on the anterior aspect of the lower leg four-finger breadth below the ST36, and one finger-breadth (middle finger) from the anterior crest of the tibia. Two different nonacupoint sites were selected for comparison. One was chosen at the tibialis anterior muscle located at middle site between the ST36 and ST37 acupoints. The other non-acupoint site located within the middle site between ST35 (Dubi: below the patella in a depression lateral to the patellar ligament with knee flexed) and ST36. The depth of injection was $2 \mathrm{~cm}$ below the skin.

\section{Intramuscular (i.m.) heating-needle stimulation}

The i.m. heating-needle stimulation was induced by a concentric stainless steel heating-needle (diameter, $1.05 \mathrm{~mm}$; length, $60 \mathrm{~mm}$ ) which was connected and feedback controlled by an inner heating therapeutic device (Model: NWX-1, Acuceuticals Co., Ltd, Shanghai, China). The heating-needle is filled with a heating element and temperature probe, which detects variations of temperature precisely $\left( \pm 0.25^{\circ} \mathrm{C}\right)$. The heating-needle was inserted unilaterally into the target acupoints, and the depth of the insertion was about $2 \mathrm{~cm}$.

\section{Intramuscular administration of hypertonic saline}

A volume of $1 \mathrm{ml} 5.8 \%$ hypertonic (HT) saline was intramuscularly infused into the trapezius contralaterally to the i.m. heating-needle stimulation to establish tonic muscle nociception. Infusion of the HT saline was performed with a 5-ml disposable syringe by a computercontrolled syringe pump (RWD Co., ShenZhen, China). A tube (extension set with polyethylene inner line) was connected from the syringe to a 27-gauge needle. The injection site was located at $2 \mathrm{~cm}$ lateral to the halfway point between the spinous process of the seventh cervical vertebra and the lateral edge of the acromion. The infusion of HT saline was performed over $1 \mathrm{~min}$.

\section{Experimental design}

In total, 50 subjects in the current study were randomly divided into different groups. In experimental session 1 , 10 subjects in each group were included for the investigation of effects of capsaicin $(100 \mu \mathrm{g} / 50 \mu \mathrm{l}) / T$ ween $80(50 \mu \mathrm{l})$ applied into the ST36/37 acupoints and nonacupoint areas. The responses of subjects exposed to Tween 80 injection were initially tested. After two weeks of the interval, the same subject received capsaicin treatment for the corresponding comparison. In the second session, the 40 subjects were included to receive a period of $15-45 \mathrm{~min}$ of $43^{\circ} \mathrm{C}$ heating-needle stimulation or needle insertion alone without heating. After two weeks of the interval, these subjects received the i.m. injection of $1 \mathrm{ml} 5.8 \% \mathrm{HT}$ saline into the trapezius together with the i.m. heating-needle stimulation.

To exclude the potential psychological influence of different treatments, the subjects remained blinded to the treatment of acupoint/non-acupoint with capsaicin/ Tween 80 , and needle stimulation with or without heating throughout the study. 


\section{Assessment of local pain and referred pain}

After the i.m. injection of Tween 80 or capsaicin at ST36/37 acupoints or non-acupoint areas, subjects assessed the ongoing pain intensity every minute for $5 \mathrm{~min}$ using a 0 to $100-\mathrm{mm}$ visual analog scale (VAS) with 0 for no pain and 100 for worst imaginable pain, followed by assessment every $5 \mathrm{~min}$ for the following $55 \mathrm{~min}$.

The subjects continuously scored the pain intensity of the i.m. $5.8 \%$ saline-induced trapezius muscle pain on a $10-\mathrm{cm}$ electronic VAS where $0 \mathrm{~cm}$ indicated 'no pain' and $10 \mathrm{~cm}$ 'intolerable pain'. The pain intensities were sampled every $5 \mathrm{~s}$ by the computer. In the subsequent analysis, the duration of the pain was assessed by onset and offset of the sampled VAS curves, the peak pain was extracted and finally, the area under the VAStime curve was calculated.

The subject drew the pain distribution on an anatomical map. The circumference was digitized, and the area was calculated (SigmaScan, Jandel Scientific, Canada). Pain around the injection site was defined as local pain, and referred pain was defined as pain occurring outside and isolated from the local pain area. In the present study, the referred pain induced by stimulation of different acupoints located within the dorsal surface of ankle (Lei et al., 2008; Lei and You, 2012), whereas posterolateral neck muscles was the most commonly referred pain area from upper trapezius muscle pain (Simons et al., 1999).

\section{Assessment of pressure pain threshold}

Pressure pain threshold (PPT) measurements were performed with a hand-held electronic algometer (Somedic AB, Stockholm, Sweden) mounted with a $1-\mathrm{cm}^{2}$ circular rubber probe. To assess the PPT, the probe was held perpendicularly and pressure-increased at a constant rate of $30 \mathrm{kPa} / \mathrm{s}$. The PPT value, where the subject felt the first change from pressure sensation to pain, was recorded. When PPT was reached, the volunteers were instructed to press a button in order to freeze the actual pressure on a digital display. The PPT was measured as the mean of three measurements at each point with an interval of $1 \mathrm{~min}$ between the measurements. In the sessions of intramuscular treatment with Tween 80/capsaicin at ST36/37 and nonST36/37 areas, the PPTs were determined at the anterior part of ankle bilaterally before the treatment, $30 \mathrm{~min}$ after the start of administration, 1-4 h, 1-2 d and 6-7 d, respectively. In the HT saline injection sessions, the PPTs were determined at the injection site and the referred pain area (the posterolateral neck muscles) prior to the injection, $30 \mathrm{~min}$ after the start of injection, $1-4 \mathrm{~h}$ and $1 \mathrm{~d}$, respectively.

\section{Assessment of heat pain threshold}

A modified heat stimulator (TaiMeng Co., Ltd, ChengDu, China) was used in the assessment of heat pain threshold (HPT). Radiant heat stimulus was a highintensity beam, 30-40\% intensity was set to induce pain sensation. The heat stimulator was $2 \mathrm{~cm}$ away from the assessed area, and a 3-mm diameter large skin area could be heated by the radiant heat stimulus. Subjects were instructed to press a hand-held button to stop the stimulation just when they felt the first sensation of pain. Three stimuli were given to each area. The mean value of the three measurements was considered as the pain threshold. The assessments of HPT were conducted before the measurement of PPTs at the same sites as PPTs measurement in the sessions mentioned above.

To familiarize the subjects with the method, the experiment was started with two pain threshold measurements. The radiant heat stimulation was shifted to a new skin area after each stimulation to avoid sensitization and fatigue during the experiment. The subjects were instructed to close their eyes during the light exposure to improve concentration.

\section{Statistical analysis}

All results were expressed as means \pm SEM. The data of VAS, PPT and heat pain threshold were analyzed using SigmaStat $^{\mathrm{TM}}$ (Systat Software Inc., California, USA) and compared by one-way/two-way analyses of variance, Student-Newman-Keuls (SNK) was performed as post hoc test. $P<0.05$ was considered as statistically significant.

\section{RESULTS}

\section{Pain intensity and distribution following the injection of capsaicin at the ST36/37 acupoints and non- acupoint areas}

As shown in Fig. 1, the i.m. administration of Tween 80 into the ST36/37 acupoints, non-ST 36/37, and non-ST35/36 areas elicited short-lasting, low-intensity pain, and small local pain distribution within the skin area over the tibialis anterior muscle. In contrast, administration with capsaicin caused longer pain duration, stronger peak pain intensity, and larger pain distribution $(P<0.001)$. Among capsaicin treatments, the pain intensity and pain distribution during the exposure to the ST36/37 acupoint treatments were significantly higher than those induced by non-acupoint area treatments (VAS peak: 6.9

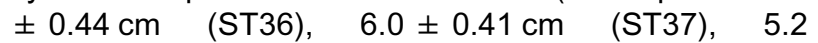
$\pm 0.36 \mathrm{~cm}$ (non-ST36/37), and $5.0 \pm 0.32 \mathrm{~cm}$ (nonST35/36); pain duration: $58 \pm 3.5 \mathrm{~min}$ (ST36), 48 $\pm 3.0 \mathrm{~min}$ (ST37), $40 \pm 2.2 \mathrm{~min}$ (non-ST36/37), and 38 \pm 2.4 min (non-ST35/36), One-Way ANOVA, $P<0.05$ ). Between treatments with capsaicin applied to the ST36 or ST37 acupoints, the pain intensity, distribution, and VAS scores following the i.m. injection of capsaicin at the ST36 acupoint was significantly higher and longer than that in the ST37 group $(P<0.05)$.

The quality of local pain after the i.m. injection of capsaicin at the ST36/37 acupoints was described by five or more subjects as 'throbbing', 'drilling', 'pressing', 'shooting', 'pressing', 'hot', 'tingling', 'heavy', 'radiating', 'nagging', 'sore', 'intense', and 'penetrating'. In contrast, the pain after the i.m. injection of capsaicin at the nonacupoint areas was described as 'throbbing', 'drilling', 'gnawing', 'hot', 'radiating', 'nagging', 'sore', 'cruel', and 'penetrating'. 


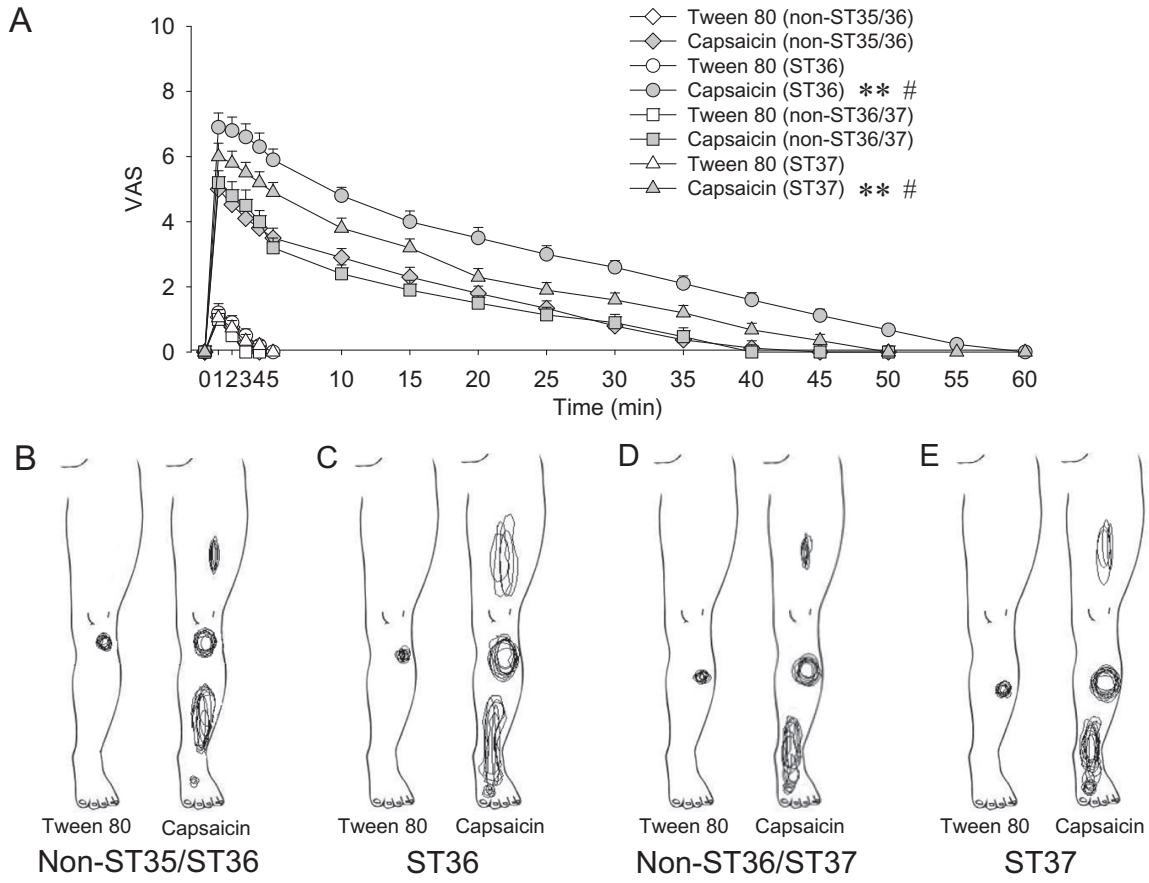

Fig. 1. The mean $(n=10)$ visual analog scale (VAS) score profile during the exposure to the injection of capsaicin $(100 \mu \mathrm{g} / 50 \mu \mathrm{l})$ into the ST36, ST37, non-ST36/37, and non-ST35/36 areas (panel 'A'). Among different treatments, the highest VAS score and VAS peak, and the longest pain duration following the capsaicin injection into the ST36 acupoint were found. Different patterns of pain distribution after the microinjection of capsaicin and Tween 80 into the areas of non-ST35/36, ST36, non-ST36/37, and ST37 were shown in panels 'B', 'C', 'D', and 'E', respectively. ** $P<0.001$ compared with the Tween 80 treatment. \# $P<0.05$ compared with the capsaicin treatment of non-ST35/36 and non-ST36/37 areas.

\section{Variations in pressure pain threshold (PPT) and heat pain threshold (HPT) at the primary injection site and the referred pain area following the i.m. treatment of the ST36/37 acupoints and non-acupoint areas with capsaicin}

Compared with Tween 80 treatment, following the i.m. injection of capsaicin, early-onset (30 min after the injection) and long-lasting (at least 2 days) mechanical hyperalgesia was observed at both the primary injection site and the referred pain area regardless the capsaicin treatment of ST36 (primary injection area: 75.36 $\pm 3.3 \%$; referred area: $85.76 \pm 3.9 \%$ ), ST37 (primary injection area: $85.44 \pm 3.2 \%$; referred area: 86.63 $\pm 4.2 \%$ ), non-ST36/37 (primary injection area: 89.65 $\pm 4.1 \%$; referred area: $92.13 \pm 4.6 \%$, and nonST35/36 (primary injection area: $91.05 \pm 4.4 \%$; referred area: $93.63 \pm 4.3 \%)$. Among capsaicin treatments, the magnitude of primary mechanical hyperalgesia in nonST36/37 treatment group and non-ST35/36 treatment group was significantly lower than those in the ST36 and ST37 groups ( $P<0.05$, two-way ANOVA, Fig. 2). In addition, there is significant difference in primary mechanical hyperalgesia between capsaicin treatment of ST36 and ST37 acupoints, during which mechanical hyperalgesia in the ST36 group was significantly higher than that in the ST37 group $(P<0.05$, two-way ANOVA, Fig. 2).

In contrast to mechanical hyperalgesia within the injection area and referred area, significantly decreased
HPT was found only at the primary injection area, but not the referred area, followed by an elevation of the HPT 1 day after the i.m. administration of capsaicin into the ST36 (primary injection area: 129.6 $\pm 5.2 \%$; referred area: 147.3 $\pm 4.2 \%$ ), ST37 (primary injection area: $121.5 \pm 4.1 \%$; referred area: $135.5 \pm 3.7 \%$ ), non-ST36/37 area (primary injection area: 113.4 $\pm 3.8 \%$; referred area: 120.3 $\pm 3.6 \%$ ), and non-ST35/36 area (primary injection area: 114.2 $\pm 3.1 \%$; referred area: 123.6 $\pm 3.9 \%)(P<0.05$ and $P<0.001)$. The heat hypoalgesia lasted around 6-7 d during the experiments. The magnitude of increases in HPT was greater in ST36 group than those of in the ST37 and non-acupoint groups $(P<0.05)$ (Fig. 2).

Influence of the i.m. $43^{\circ} \mathrm{C}$ nonpainful heating-needle stimulation applied to the ST36 acupoint in modulation of pressure pain threshold (PPT) and heat pain threshold (HPT)

We observed variations of mean PPTs and HPTs in dorsal surface of ankle prior to and post the i.m. $43^{\circ} \mathrm{C}$ heating-needle stimulation, which was applied to the ST36 acupoint. A period of i.m. 15- to $45-\mathrm{min} 43^{\circ} \mathrm{C}$ heating-needle stimulation ipsilaterally applied to the ST36 acupoint failed to cause any effects on the bilateral PPTs $(P>0.05$, Fig. 3A), whereas elevated bilateral HPTs (heat hypoalgesia) were significantly observed after the $30-45 \mathrm{~min}$, but not $15 \mathrm{~min}$, of the i.m. $43^{\circ} \mathrm{C}$ heating-needle stimulation $(P<0.05$, Fig. 3B). The elevations of HPTs induced by the exposure to the i.m. $43^{\circ} \mathrm{C}$ heating-needle stimulation returned to the baseline level over time within 1-2 d. In contrast to heating-needle stimulation, a period of i.m. 45-min needle insertion alone without heating did not cause any effects on bilateral PPTs and HPTs (Fig. 3).

Influence of $15-$ to $45-\mathrm{min} 43^{\circ} \mathrm{C}$ heating-needle stimulation applied to the ST 36 acupoint on tonic trapezius muscle pain elicited by the i.m. injection of $5.8 \%$ saline

Fig. 4A shows the pain distribution after the i.m. injection of $1 \mathrm{ml} 5.8 \%$ saline into the unilateral trapezius. Fig. 4B-D illustrates the influence of a period of 15- to 45-min $43^{\circ} \mathrm{C}$ heating-needle stimulation applied to the contralateral ST36 acupoint on pain distribution elicited by the i.m. $1 \mathrm{ml} 5.8 \%$ saline into the trapezoid muscle. Compared with the control group receiving the $5.8 \%$ saline injection alone (primary injection area: 1014.6 \pm 76.4 ; referred area: $315.9 \pm 26.4$ ), 30 - to $45-\mathrm{min}$, but 
A Mechanical responses

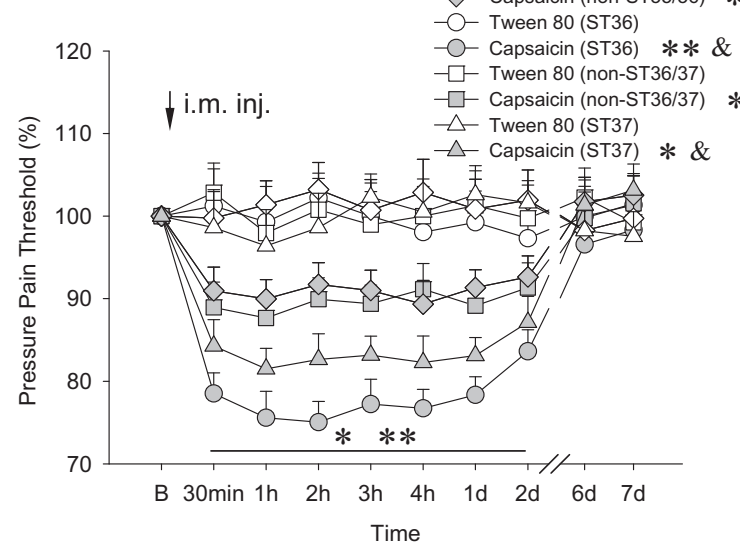

B Heat responses

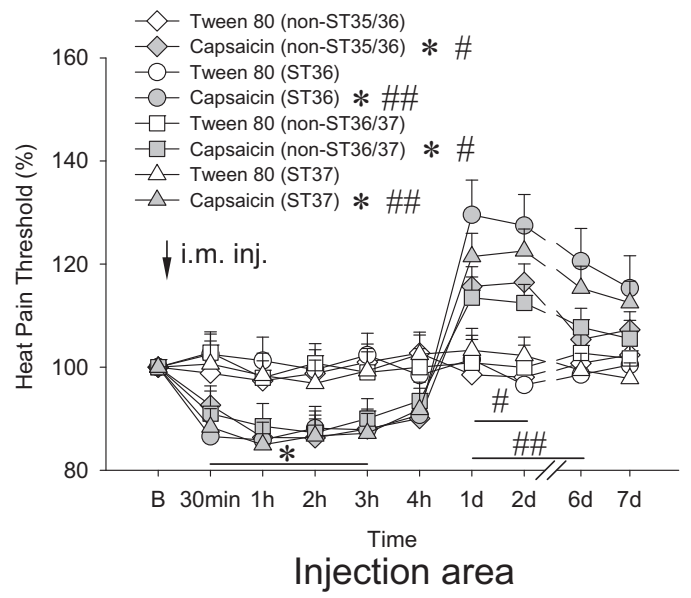

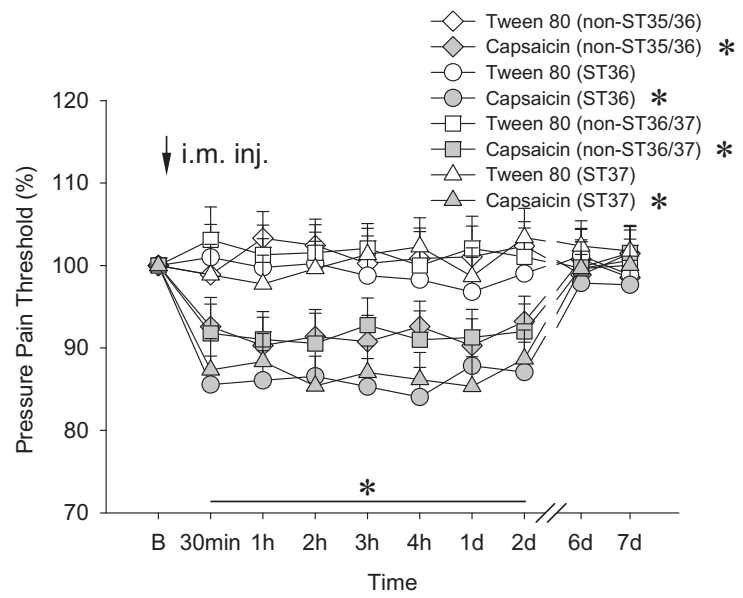

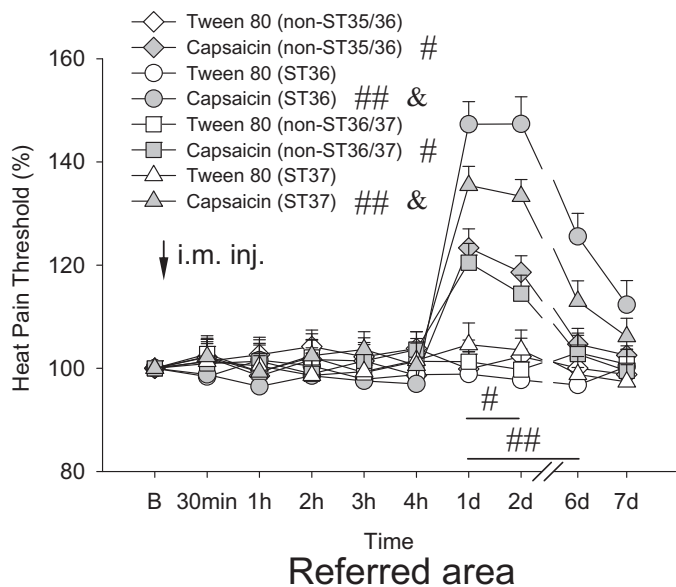

Fig. 2. Variations of mean pressure pain thresholds (PPT) and heat pain thresholds (HPT) in the primary injection area and the referred area located within the dorsal surface of ankle, which were measured prior to and post the different injections of capsaicin $(100 \mu \mathrm{g} / 50 \mu \mathrm{l})$ into the ST36/37 acupoints, non-ST36/37 area, and non-ST35/36 area. ${ }^{*} P<0.05$, \# $P<0.05,{ }^{* *} P<0.001$, \#\# $P<0.001$ compared with the PPT and HPT prior to the capsaicin injection. \& $P<0.05$ compared with the changes in PPT and HPT post the capsaicin injection at non-ST35/36 and non-ST36/37 areas. (B: baseline response) (10 subjects in each group).

not 15-min, heating-needle stimulation applied to the contralateral ST36 acupoint significantly reduced the $5.8 \%$ saline intramuscularly induced pain distribution (15-min heating-needle stimulation: primary injection area $(1136.8 \pm 75.8)$, referred area $(337.6 \pm 32.1)$; 30min heating-needle stimulation: primary injection area (772.4 \pm 52.3), referred area (201.9 \pm 20.7$)$; 45-min heating-needle stimulation: primary injection area (744.6 $\pm 48.1)$, referred area $(226.5 \pm 22.4) ; \quad P<0.05$, respectively). Among different treatments, the i.m. 5.8\% saline alone evoked significantly larger local muscle pain around the primary injection site and the referred pain area $(6 / 10$ subjects in the control group; $8 / 10$ subjects in the 15-min heating-needle stimulation; $5 / 10$ subjects in the 30-min heating-needle stimulation; $3 / 10$ subjects in the 45-min heating-needle stimulation) located in the posterolateral aspects of the neck $(P<0.05)$. In addition, $4 / 10$ subjects in the control group; $5 / 10$ subjects in the 15-min heating-needle stimulation group reported referred pain to the temporomandibular region.

Fig. 5 exhibits the VAS score profile of the trapezius muscle pain elicited by the i.m. injection of $1 \mathrm{ml} 5.8 \%$ saline, and effects of pre-emptive treatment with different periods (15-45 min) of $43^{\circ} \mathrm{C}$ heating-needle stimulation applied onto the contralateral ST36 acupoint. Among the different treatments, the i.m. injection of $5.8 \%$ HT saline caused the longest pain duration and the strongest peak pain intensity $(P<0.05)$. Compared with the VAS scores elicited by the i.m. $5.8 \%$ saline, a period of 30 - to $45-\mathrm{min}$, but not $15-\mathrm{min}, 43^{\circ} \mathrm{C}$ heatingneedle stimulation significantly depressed the VAS score during the trapezius muscle pain (Table 1).

\section{Effects of pre-emptive treatment with $43^{\circ} \mathrm{C}$ heating- needle stimulation on pain pressure threshold (PPT) and heat pain threshold (HPT) at the primary injection area and the referred area following the i.m. injection of $5.8 \%$ saline into the trapezius}

Compared with the baseline response, a significant decrease in PPT after the i.m. injection of $1 \mathrm{ml} 5.8 \%$ saline into the trapezius was found at the primary injection area and the referred area (injection area: 81.9 $\pm 6.4 \%$; referred pain area: $87.2 \pm 5.6 \%, P<0.05)$, and the decreased PPT at both the injection area and the referred pain area gradually returned to the baseline 
A Mechanical responses
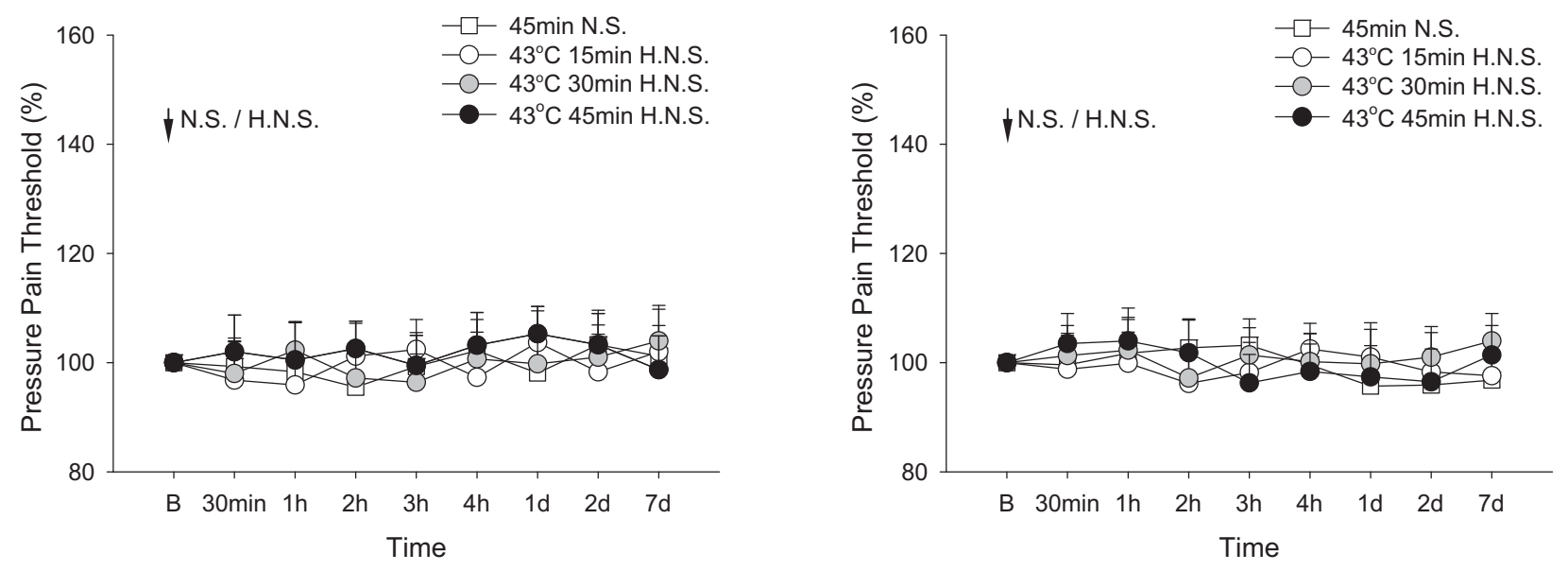

\section{B Heat responses}
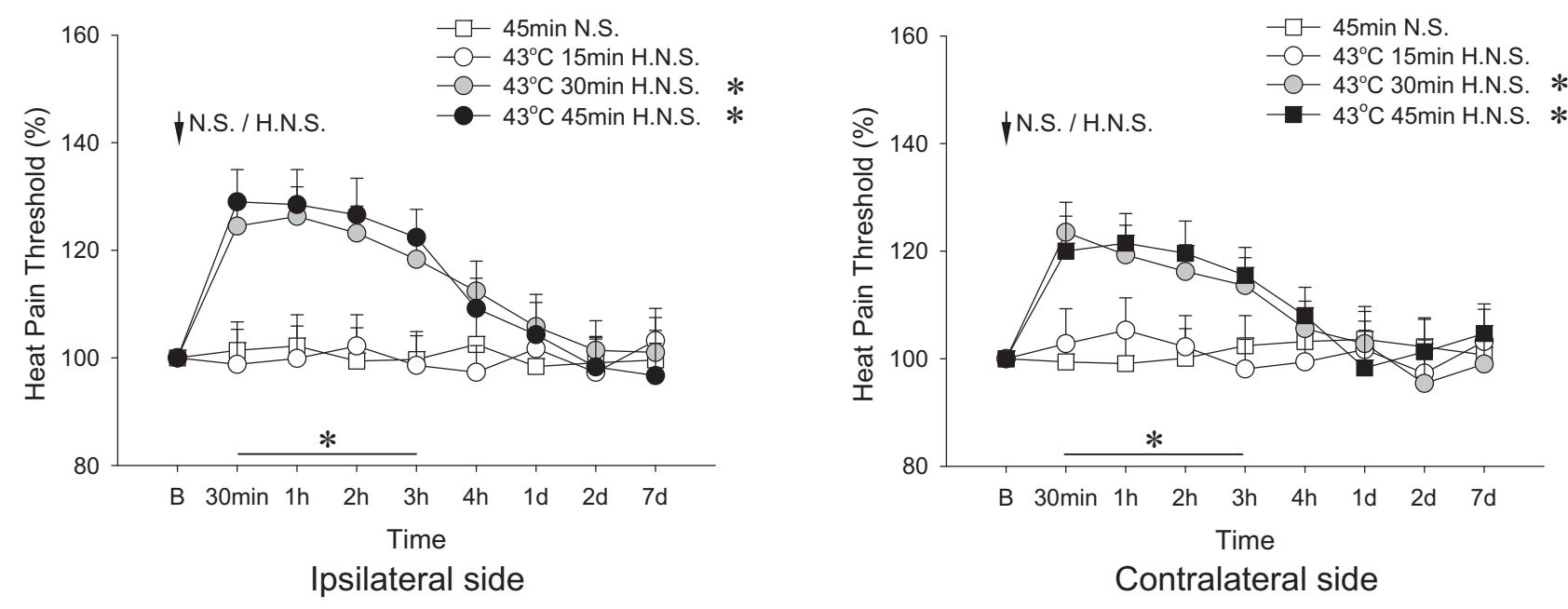

Fig. 3. Variations of bilateral mean pressure pain thresholds (PPT) and heat pain thresholds (HPT) in dorsal surface of ankle measured prior to and post the i.m. heating-needle stimulation (H.N.S.) applied to the ST36 acupoint. ${ }^{*} P<0.05$ compared with 15 -min $43^{\circ} \mathrm{C}$ heating-needle stimulation. (B: baseline response) (N.S.: needle stimulation without heating) (10 subjects in each group).

level within $1 \mathrm{~d}$ after the i.m. $5.8 \%$ saline injection (Fig. 6A).

In contrast to mechanical hyperalgesia during the $5.8 \%$ saline-induced muscle pain, heat hyperalgesia was found only at the primary injection area, but not the referred area (Fig. 6B). At the local injection site, preemptive treatment with $30-$ to $45-\mathrm{min}$, but not $15-\mathrm{min}$, $43^{\circ} \mathrm{C}$ heating-needle stimulation applied to the contralateral ST36 acupoint significantly blocked the i.m. $5.8 \%$ saline-induced heat hyperalgesia (Fig. 6B). At the referred pain area, significant heat hypoalgesia was found after the pre-emptive treatment with 30 - to 45min, but not $15-\mathrm{min}, 43^{\circ} \mathrm{C}$ heating-needle stimulation applied to the contralateral ST36 acupoint $(P<0.05$, Fig. 6B).

\section{DISCUSSION}

In the present study, the major findings are that the i.m. administration of capsaicin at acupoint and non-acupoint site exhibit different effects on the perception of pain.
Compared with the non-acupoint treatment, treatment of ST36 or ST37 acupoints with capsaicin caused the strongest pain intensity and the largest pain distribution, followed by rapid onset, bilateral, long-lasting secondary mechanical hyperalgesia and slower onset secondary heat hypoalgesia. The $43^{\circ} \mathrm{C}$ non-painful heating-needle stimulation applied to the ST36 acupoint significantly depressed upper contralateral trapezoid muscle pain induced by i.m. injection of $5.8 \%$ saline.

\section{Difference in pain and its modulation following treatment of acupoint and non-acupoint with capsaicin}

It is well known that capsaicin is a naturally occurring alkaloid derived from chili peppers. Capsaicin-related compounds can be ideally selected as screening tools for exciting peripheral capsaicin-sensitive fibers, particularly C-fibers, and for exploring pain and its modulation in animals as well as humans. From molecular perspective, capsaicin binds to the transient receptor potential vanilloid 1 (TRPV1) which is 
A i.m. HT saline
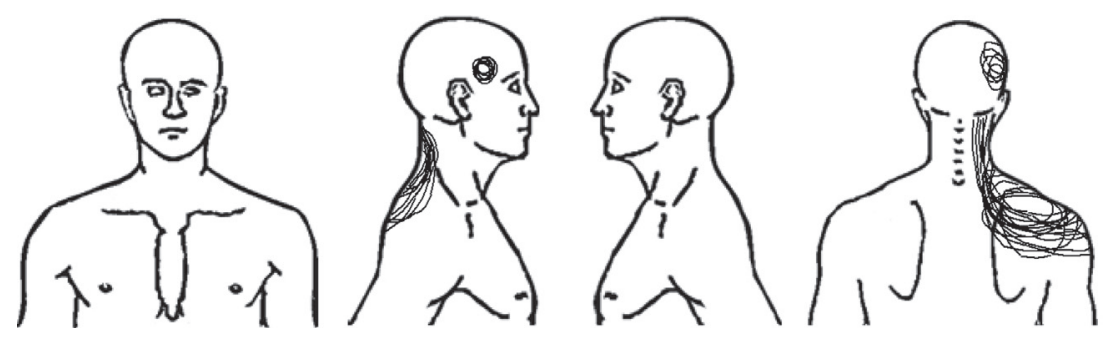

B $43^{\circ} \mathrm{C} 15 \mathrm{~min}$ H.N.S. + i.m. HT saline
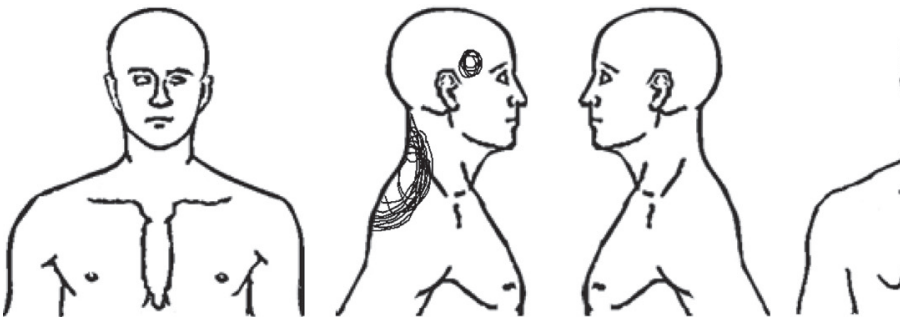

C $43^{\circ} \mathrm{C} 30 \mathrm{~min}$ H.N.S. + i.m. HT saline
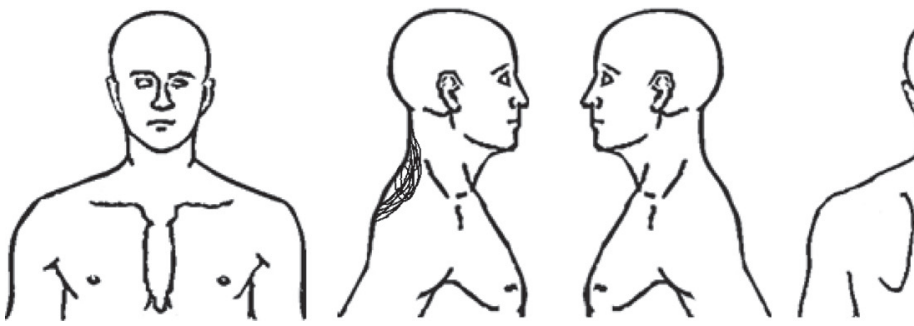

D $43^{\circ} \mathrm{C} 45 \mathrm{~min}$ H.N.S. + i.m. HT saline

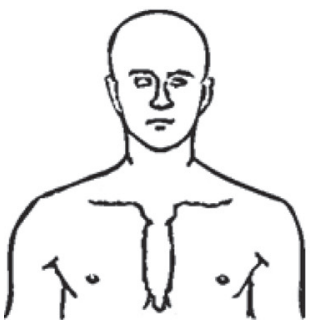

Anterior

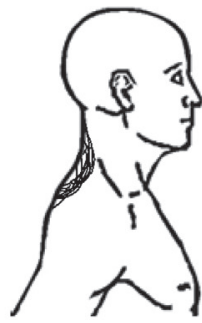

Right side

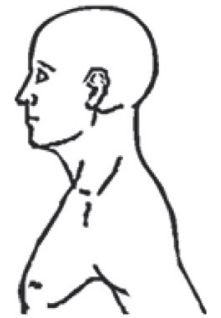

Left side

Fig. 4. Different patterns of pain distribution within the area of trapezius muscle pain exposed to the i.m. injection of $1 \mathrm{ml} 5.8 \%$ (HT: hypotonic) saline, or $15-$ to $45-\mathrm{min} 43^{\circ} \mathrm{C}$ heating-needle stimulation (H.N.S.) applied to the contralateral ST36 acupoint. A period of $30-$ to $45-\min 43^{\circ} \mathrm{C}$ heating-needle stimulation significantly reduced the pain distribution elicited by the i.m. $5.8 \%$ saline injection within the trapezius.

expressed predominantly by sensory neurons (Cortright and Szallasi, 2004). The activity of the TRPV1 receptors in sensory nerves has been reported to cause sensations varying from hotness to burning sensation, and even resulting in depression of nociception and pain (Crayton et al., 1981; Della Torre et al., 1996; Marchettini et al., 1996; Gjerstad et al., 2000; Sluka, 2002; You et al., 2010).

In the present study, we demonstrated that effects of treatment of acupoint and non-acupoint with capsaicin differed significantly, initially suggesting the importance of capsaicin-sensitive afferents located within the
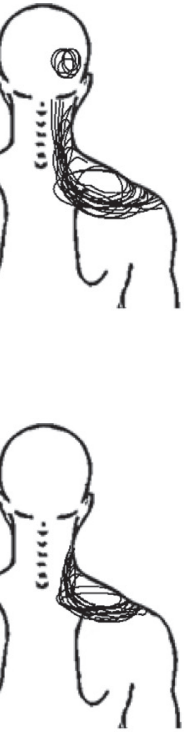

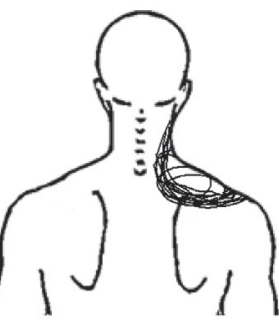

Posterior acupoint areas in the perception of pain. In manual acupuncture, the major involvement of $\mathrm{C}$ afferents was proved in acupuncture-induced analgesia (Zhu et al., 1990). Earlier investigations further showed that there are dense distributions of $\mathrm{C}$ fibers at the area of acupoint ( $\mathrm{Li}$ et al., 2004; Silberstein, 2012), and that the acupoints may contain a significantly higher number of TRPV1positive nerve fibers compared with non-acupoint area (Abraham et al., 2011). From functional perspective, previous study reported that the higher the intensity of electrical stimulation used for activating C-fibers, the more pronounced the stimulationproduced analgesia, which finding further supports the importance of Cafferents in electroacupuncture- and acupoint-induced analgesia (You et al., 2006).

Acupuncture to Zusanli (ST36) has been reported to be more effective in pain relief and decrease in narcotic requirements after surgery (Wang et al., 2015). In the present study, we also found that the effects of capsaicin treatment of ST36 and ST37 differed significantly. Previous study in humans showed that the $5.8 \%$ saline-induced muscle pain at areas of tendon and proximal tendon-bone junction has significantly higher VAS score compared with that at the muscle belly site (Gibson et al., 2006). From anatomical perspective, ST36 acupoint locates close to the tendon area, whereas the ST37 acupoint locates around the muscle belly of the tibialis anterior muscle. Thus, pronounced pain elicited by capsaicin treatment of non-ST35/36 area, which is more proximal to the tendon and tendonbone junction, would be expected. Contrary to expectations, capsaicin stimulation of this non-ST35/36 area did not elicit a significant difference compared with the treatment of nonST36/37 area (Fig. 1). From this point of view, the difference in the effects of stimulation might be dependent on the characteristics of acupoint per se rather than its spatial location.

\section{Difference and mechanisms between descending inhibitory modulation induced by acupoint treatment and DNIC}

The present study reported that capsaicin-sensitive fibers within the both ST36/37 acupoints and non-acupoint 


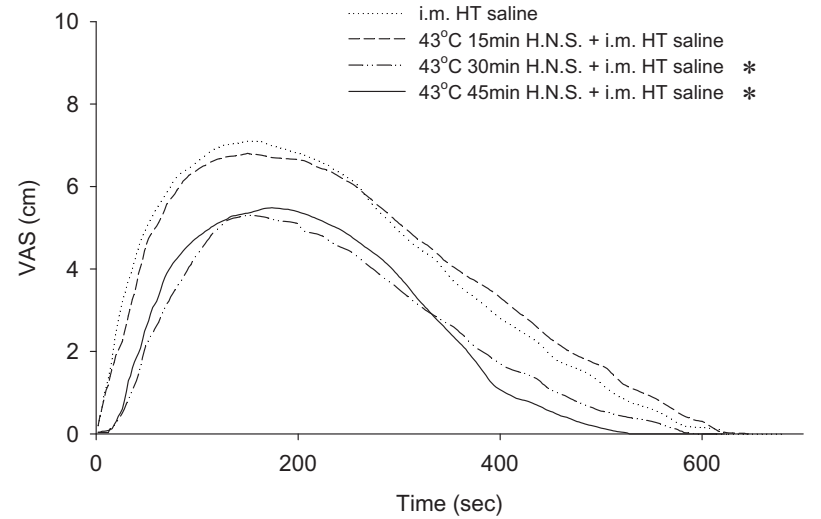

Fig. 5. Effects of the i.m. pre-emptive $43^{\circ} \mathrm{C}$ heating-needle stimulation (H.N.S.) applied to the ST36 acupoint on the mean $(n=10)$ visual analog scale (VAS) score profile of the trapezoid muscle pain elicited by the i.m. injection of $5.8 \%(\mathrm{HT})$ saline. ${ }^{*} P<0.05$ compared with the i.m. HT saline injection group, and $15-\min 43^{\circ} \mathrm{C}$ heatingneedle stimulation group. Please note that the standard error bars were not shown due to the limited space available for the legible exhibition of experimental data collected per $5 \mathrm{~s}$. (10 subjects in each group).

areas were involved in the perception of pain, and heatsensitive fibers participated in non-painful heatingneedle stimulation-induced analgesia. However, we found that the capsaicin treatment of the ST36/37 acupoints versus non-acupoint areas elicited different pain intensities, pain distributions, and responses to noxious stimuli of different modalities. This finding, to some extent, suggested characteristics of topographical specificity; the dense and distribution of capsaicinsensitive fibers in areas of ST36/37 and non-acupoints might be different, of acupoint in contrast to nonacupoint area. One of the most important findings of the current study is that the i.m. heat stimulation at a nonpainful temperature, i.e. $43^{\circ} \mathrm{C}$, applied to the ST36 acupoint significantly reduced shoulder muscle pain; this included reduction of pain intensity, pain distribution area, mechanical hyperalgesia, and sensation to noxious heat stimuli. Taken together, these findings support a significant difference between the analgesia effects induced by DNIC and the stimulation of acupoint by non-painful heating-needle stimulation.

Our previous animal studies showed that both descending facilitatory and inhibitory modulations are 'silent' during the physiological state, and can be activated by sufficient excitement of C-afferents (You et al., 2010, 2013). Here, following the injection of capsaicin intramuscularly at the ST36/37 acupoints, both rapid onset mechanical hyperalgesia and delayed heat hypoalgesia were found at the referred pain area (ankle), suggesting the initiation of descending facilitatory and inhibitory control of nociception, respectively. This result as well as the data related to the analgesia effects of non-painful heating-needle stimulation is consistent with results of earlier neurophysiological and behavioral studies demonstrating that the analgesia effect resulting from acupoint stimulation in muscle is mediated by the descending inhibitory system; i.e., the periaqueductal gray (PAG), the reticular formation of the brain stem, and dorsolateral fasciculus of the spinal cord (Wu et al., 1974; Liu et al., 1990; You et al., 2006; Lei and You, 2013; Wang et al., 2014; Lei et al., 2014). This descending inhibitory pathway involves various neurotransmitters, such as opioid peptides (Mayer et al., 1977; Han et al., 1984; Zadina et al., 1997; Fields et al., 2006; You et al., 2014), cholecystokinin octapeptide (Ito et al., 1982; Zhou et al., 1993; Ko et al., 2006), and noradrenalin (Zhao and Duggan, 1988; Lei et al., 2011; For reviews see Han, 2003; Zhao, 2008).

In this study, intramuscularly treatment with capsaicin at the non-ST35/36 and non-ST36/37 sites could also trigger the descending control on pain as well as capsaicin at the ST36/37 acupoints. The difference was, however, that the treatment of ST36/37 produced a stronger effect than that of non-acupoint sites (Fig. 1). Our preliminary unpublished experiments showed that needling non-acupoints resulted in local sensations around non-acupoints, and very low sensations along meridians in most of the subjects. In contrast, needling acupoints induced stronger sensations at the acupoint and in the meridians. In an earlier electromyogram study, muscle discharge signals at the stimulated acupoints had a higher frequency and were significantly stronger than at the control points (Chen, 2002). More profound effect induced by treatment of acupoint, rather that non-acupoint area, found here and in other studies may depend on activation of a wide spectrum of myelinated and unmyelinated nerve fibers, particularly the slower conducting fibers in the tendino-muscular layers, within the acupoint (Hui et al., 2007). Taken these findings together, our present data support the proposal that there are distinct differences between treatment of an acupoint versus non-acupoint, and these might be depended on different distributions of afferents, and the modulation through different brain circuitries (Takeshige, 1985; You et al., 2014).

\section{Pre-emptive analgesia and non-painful heat stimulation-induced descending inhibition of pain}

Pre-emptive analgesia indicates that an analgesic intervention is started before the noxious stimulus arises

Table 1. Average VAS parameter (mean \pm SEM) during intramuscular injection of 1 ml $5.8 \%$ (HT) saline into the trapezius muscle

\begin{tabular}{llll}
\hline & i.m. HT saline & $\begin{array}{l}43^{\circ} \mathrm{C} 15 \text { min H.N.S. }+ \\
\text { i.m. HT saline }\end{array}$ & $\begin{array}{l}43^{\circ} \mathrm{C} 30 \mathrm{~min} \mathrm{H.N.S.}+ \\
\text { i.m. HT saline }\end{array}$ \\
\hline VAS area (cm s) & $1207.39 \pm 152.6$ & $1191.64 \pm 144.9$ & $771.56 \pm 92.6^{*}$ \\
VAS peak (cm) & $7.10 \pm 0.56$ & $6.81 \pm 0.64$ & $5.30 \pm 0.38^{*}$ \\
VAS duration (s) & $642 \pm 42$ & $624 \pm 38$ & $568 \pm 32^{*}$ \\
\hline
\end{tabular}


A Mechanical responses

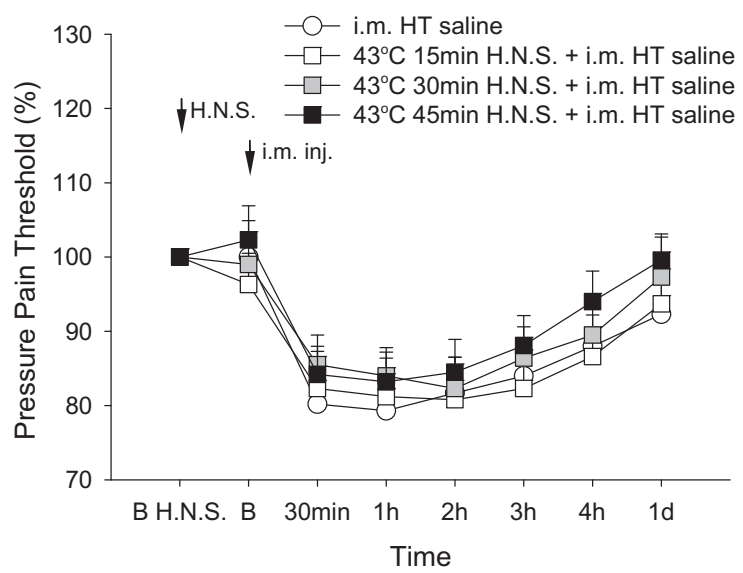

B Heat responses

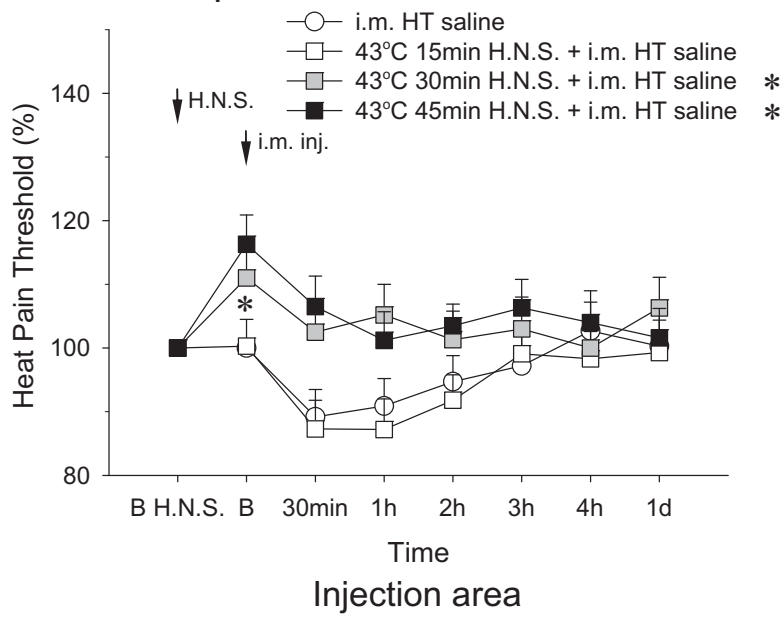

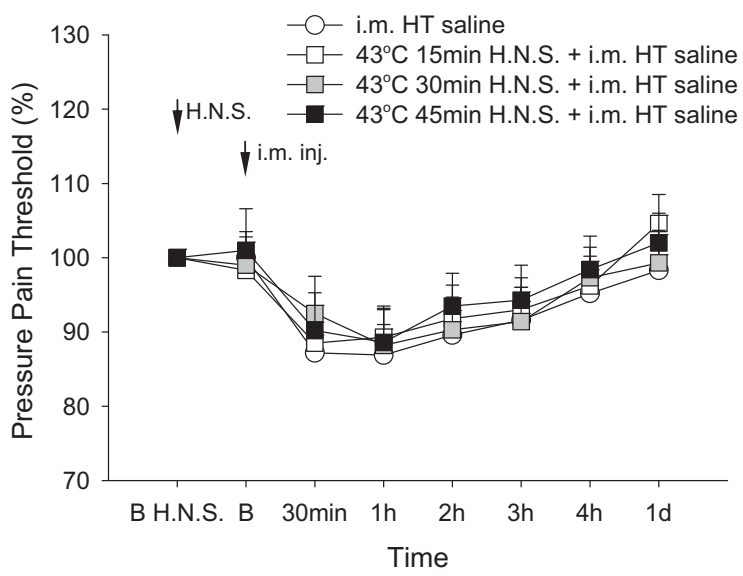

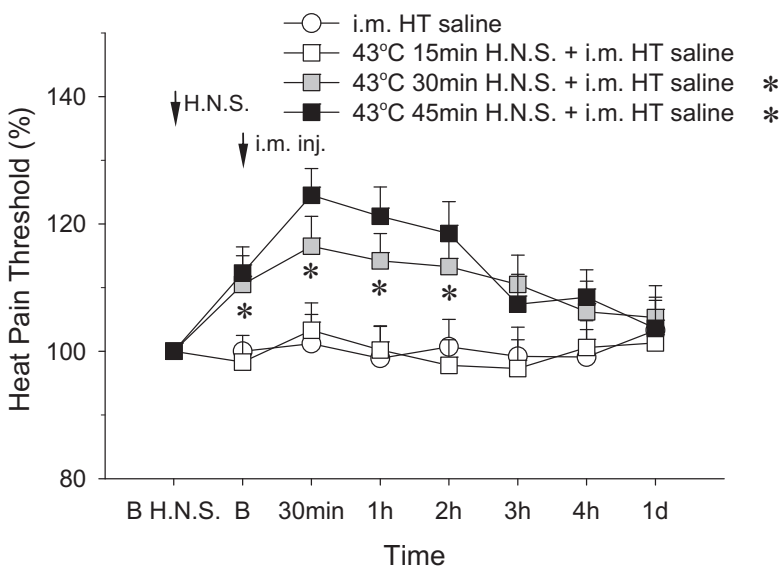

Referred area

Fig. 6. Variations of mean pressure pain threshold (PPT) and heat pain threshold (HPT) in the primary injection area and the referred pain area of trapezius muscle pain elicited by the i.m. injection of $5.8 \%$ (HT) saline associated with different periods (15-45 min) of $43^{\circ} \mathrm{C}$ heating-needle stimulation (H.N.S.) applied to the contralateral ST36 acupoint. ${ }^{*} P<0.05$ compared with the HPT prior to the i.m. injection of HT saline. (B H.N.S.: before heating-needle stimulation) (B: response before the i.m. injection) (10 subjects in each group).

in order to block the occurrence and development of nociception (Crile, 1913). The goal of pre-emptive analgesia is to decrease acute pain induced by tissue injury intraoperatively, and to inhibit the postoperative development of persistent or chronic pain (Woolf and Chong, 1993). Different analgesics medications such as nonsteroidal anti-inflammatory drugs (NSAIDs), opioids, ketamine, dextromethorphan or peripheral local anesthetics are applied clinically to induce pre-emptive analgesia (Dahl and Møiniche, 2004). In the clinic, tolerance, addiction to opioids, and various side-effects may limit use of these pharmacological treatments. In the present study, pronounced descending pain inhibitory effect was induced by non-painful $\left(43^{\circ} \mathrm{C}\right)$ heating-needle stimulation when treating pain in the trapezoid muscle. It is known that warm fibers are mostly C-fibers (LaMotte and Campbell, 1978; Pertovaara and Kojo, 1985). Together with previous experimental results in animals (You et al., 2014), the results of the present human study suggest that nonpainful heat stimulus applied at acupoint could be a valid method in activating $\mathrm{C}$-fibers and triggering descending inhibitory controls. The non-painful heating-needle stimu- lation may bypass the lower triggering threshold of descending facilitation, and directly excite the descending inhibition associated with higher triggering threshold (You et al., 2014). As such, the non-painful heating stimulation might be a promising, alternative approach to reduce the analgesic requirement and analgesic-related adverse effects of pre-emptive analgesia treatment (Chen et al., 1998; You et al., 2016).

In summary, the present study provides direct evidence for differences between treatments of acupoint and non-acupoints, and demonstrates the efficacy of non-painful heating-needle stimulation in modulation of pain in human subjects. Based on diffuse characteristics of endogenous descending controls, the experimental results also provide evidence that is in line with the Chinese traditional therapeutic regime: upper diseasebottom management, left complaint-right treatment.

\section{CONFLICT OF INTEREST STATEMENT}

All authors declare no personal or financial conflict of interests. 


\section{Acknowledgments-The present work was supported by grants from National Natural Science Foundation of China (81473752) and "the Fundamental Research Funds for the Central Universities".}

\section{REFERENCES}

Abraham TS, Chen ML, Ma SX (2011) TRPV1 expression in acupuncture points: response to electroacupuncture stimulation. J Chem Neuroanat 41:129-136.

Besson JM, Chaouch A (1987) Peripheral and spinal mechanisms of nociception. Physiol Rev 67:67-186.

Chen L, Tang J, White PF, Sloninsky A, Wender RH, Naruse R, Kariger R (1998) The effect of location of transcutaneous electrical nerve stimulation on postoperative opioid analgesic requirement: acupoint versus nonacupoint stimulation. Anesth Analg 87:1129-1134.

Chen E (2002) Subjective evidences and propagated sensation transmission (proof of the power and arousal of Chi). Clin Acupunct Oriental Med 3:138-165.

Chiang CY, Chang CT, Chu HC, Yang LF (1973) Peripheral afferent pathway for acupuncture analgesia. Sci Sin 16:210-217.

Cortright DN, Szallasi A (2004) Biochemical pharmacology of the vanilloid receptor TRPV1. An update. Eur J Biochem 271:1814-1819.

Crayton SC, Mitchell JH, Payne FC (1981) Reflex cardiovascular response during injection of capsaicin into skeletal muscle. Am J Physiol 240:315-319.

Crile GW (1913) The kinetic theory of shock and its prevention through anoci-association (shockless operation). Lancet 185:7-16.

Cui KM, Li WM, Gao X, Chung JM, Wu GC (2005) Electroacupuncture relieves chronic visceral hyperalgesia in rats. Neurosci Lett 376:20-23.

Dahl JB, Møiniche S (2004) Pre-emptive analgesia. Br Med Bull 71:13-27.

Della Torre G, Lucchi ML, Brunetti O, Pettorossi VE, Clavenzani P, Bortolami R (1996) Central projections and entries of capsaicinsensitive muscle afferents. Brain Res 713:223-231.

Fields HL, Basbaum Al, Heinricher MM (2006) Central nervous system mechanisms of pain modulation. In: McMahon $\mathrm{S}$, Koltzenburg M, editors. Wall and Melzack's Textbook of Pain. London: Elsevier.

Gibson W, Arendt-Nielsen L, Graven-Nielsen T (2006) Referred pain and hyperalgesia in human tendon and muscle belly tissue. Pain 120:113-123.

Gjerstad J, Tjølsen A, Svendsen F, Hole K (2000) Inhibition of spinal nociceptive responses after intramuscular injection of capsaicin involves activation of noradrenergic and opioid systems. Brain Res 859:132-136.

Han JS, Xie GX, Zhou ZF, Folkesson R, Terenius L (1984) Acupuncture mechanisms in rabbits studied with microinjection of antibodies against beta-endorphin, enkephalin and substance P. Neuropharmacology 23:1-5.

Han JS (2003) Acupuncture: neuropeptide release produced by electrical stimulation of different frequencies. Trends Neurosci 26:17-22.

Hardy JD, Wolff HG, Goodell H (1952) Pain sensations and reactions. Baltimore: Williams \& Wilkins.

Hui KK, Nixon EE, Vangel MG, Liu J, Marina O, Napadow V, Hodge SM, Rosen BR, Makris N, Kennedy DN (2007) Characterization of the "deqi" response in acupuncture. BMC Complement Altern Med 7:33.

Ito S, Katssura G, Maeda Y (1982) Caerulein and CCK suppress endorphin induced analgesia in the rat. Eur $\mathrm{J}$ Pharmacol 80:270-289.

Kawakita K, Funakoshi M (1982) Suppression of the jaw-opening reflex by conditioning a-delta fiber stimulation and electroacupuncture in the rat. Exp Neurol 78:461-465.
Ko ES, Kim SK, Kim JT, Lww G, Han JB, Rho SW, Hong MC, Bae H, Mim BI (2006) The difference in mRNA expressions of hypothalamic CCK and CCK-A and -B receptors between responder and non-responder rats to high frequency electroacupuncture analgesia. Peptides 27:1841-1845.

LaMotte RH, Campbell JN (1978) Comparison of responses of warm and nociceptive C-fiber afferents in monkey with human judgements of thermal pain. J Neurophysiol 41:509-528.

Le Bars D, Dickenson AH, Besson JM (1979) Diffuse noxious inhibitory controls (DNIC). I. Effects on dorsal horn convergent neurones in the rat. Pain 6:283-304.

Lei J, You HJ (2012) Variation of pain and vasomotor responses evoked by intramuscular infusion of hypertonic saline in human subjects: influence of gender and its potential neural mechanisms. Brain Res Bull 87:564-570.

Lei J, You HJ (2013) Endogenous descending facilitation and inhibition differ in control of formalin intramuscularly induced persistent muscle nociception. Exp Neurol 248:100-111.

Lei J, You HJ, Andersen OK, Graven-Nielsen T, Arendt-Nielsen L (2008) Homotopic and heterotopic variation in skin blood flow and temperature following experimental muscle pain in humans. Brain Res 1232:85-93.

Lei J, Jin L, Zhao Y, Sui MY, Huang L, Tan YX, Chen YK, You HJ (2011) Sex-related differences in descending norepinephrine and serotonin controls of spinal withdrawal reflex during intramuscular saline induced muscle nociception in rats. Exp Neurol 228:206-214.

Lei J, Sun T, Lumb BM, You HJ (2014) Roles of the periaqueductal gray in descending facilitatory and inhibitory controls of intramuscular hypertonic saline induced muscle nociception. Exp Neurol 257:88-94.

Leung A, Khadivi B, Duann JR, Cho ZH, Yaksh T (2005) The effect of Ting point (tendinomuscular meridians) electroacupuncture on thermal pain: a model for studying the neuronal mechanism of acupuncture analgesia. J Altern Complement Med 11:653-661.

Levine JD, Gormley J, Fields HL (1976) Observations on the analgesic effects of needle acupuncture (acupuncture). Pain 2:149-159.

Li AH, Zhang JM, Xie YK (2004) Human acupuncture points mapped in rats are associated with excitable muscle/skin-nerve complexes with enriched nerve endings. Brain Res 1012:154-159.

Liu X, Jiang MC, Huang PB, Zou T (1990) Role of afferent C fibers in electroacupuncture of "zusanli" point in activating nucleus raphe magnus. Acta Physiol Sin 42:523-533.

Lu GW (1983) Characteristics of afferent fiber innervation on acupuncture points zusanli. Am J Physiol 245:R606-612.

Marchettini P, Simone DA, Caputi G, Ochoa JL (1996) Pain from excitation of identified muscle nociceptors in humans. Brain Res 740:109-116.

Mayer DJ, Price DD, Raffi A (1977) Antagonism of acupuncture analgesia in man by narcotic antagonist naloxone. Brain Res 121:368-372.

Melzack R, Wall PD (1965) Pain mechanisms: a new theory. Science 150:971-979.

Pertovaara A, Kojo I (1985) Influence of the rate of temperature change on thermal thresholds in man. Exp Neurol 87:439-445.

Pomeranz B, Chiu D (1976) Naloxone blockade of acupuncture analgesia: endorphin implicated. Life Sci 19:1757-1762.

Radhakrishnan R, Sluka KA (2005) Deep tissue afferents, but not cutaneous afferents, mediate transcutaneous electrical nerve stimulation-induced antihyperalgesia. J Pain 6:673-680.

Silberstein M (2012) Do acupuncture meridians exist? Correlation with referred itch (mitempfindung) stimulus and referral points. Acupunct Med 30:17-20.

Simons DG, Travell JG, Simons LS (1999). In: Travell \& Simons' myofascial pain and dysfuction: the trigger point manual Volume 1 Upper half of body. Philadelphia: Lippincott William \& Wilkins. p. 278-307.

Sluka KA (2002) Stimulation of deep somatic tissue with capsaicin produces long-lasting mechanical allodynia and heat hypoalgesia that depends on early activation of the cAMP pathway. J Neurosci 22:5687-5693. 
Takeshige C (1985) Differentiation between acupuncture and nonacupuncture points by association with analgesia inhibitory system. Acupunct Electrother Res 10:195-202.

Wang B, Tang J, White PF, Naruse R, Sloninsky A, Kariger R, Gold J, Wender RH (1997) Effect of the intensity of transcutaneous acupoint electrical stimulation on the postoperative analgesic requirement. Anesth Analg 85:406-413.

Wang K, Xiang XH, Qiao N, Qi JY, Lin LB, Zhang R, Shou XJ, Ping XJ, Han JS, Han JD, Zhao GP, Cui CL (2014) Genomewide analysis of rat periaqueductal gray-dorsal horn reveals time-, region- and frequency-specific mRNA expression changes in response to electroacupuncture stimulation. Sci Rep 4:6713.

Wang M, Gao YH, Xu J, Chi Y, Wei XB, Lewith G, Liu JP (2015) Zusanli (ST36) acupoint injection for preventing postoperative ileus: A systematic review and meta-analysis of randomized clinical trials. Complement Ther Med 23:469-483.

Woolf CJ, Chong MS (1993) Preemptive analgesia-Treating postoperative pain by preventing the establishment of central sensitization. Anesth Analg 77:363-379.

Wu CP, Chao CC, Wei JY (1974) Inhibitory effect produced by stimulation of afferent nerves on responses of cat dorsolateral fasciculus fibers to nocuous stimulus. Sci Sin 27:688-697.

You HJ, Cao DY, Yuan B, Arendt-Nielsen L (2006) Sex differences in the responses of spinal wide-dynamic range neurons to subcutaneous formalin and in the effects of different frequencies of conditioning electrical stimulation. Neuroscience 138:1299-1307.

You HJ, Lei J, Sui MY, Huang L, Tan YX, Tjølsen A, Arendt-Nielsen L (2010) Endogenous descending modulation: spatiotemporal effect of dynamic imbalance between descending facilitation and inhibition of nociception. J Physiol 588:4177-4188.

You HJ, Lei J, Niu N, Yang L, Fan XL, Tjølsen A, Li Q (2013) Specific thalamic nuclei function as novel 'nociceptive discriminators' in the endogenous control of nociception in rats. Neuroscience 232:53-63.

You HJ, Lei J, Ye G, Fan XL, Li Q (2014) Influence of intramuscular heat stimulation on modulation of nociception: complex role of central opioid receptors in descending facilitation and inhibition. J Physiol 592:4365-4380.

You HJ, Lei J, Xiao Y, Ye G, Sun ZH, Yang L, Niu N (2016) Preemptive analgesia and its supraspinal mechanisms: enhanced descending inhibition and decreased descending facilitation by dexmedetomidine. J Physiol 594:1875-1890.

Zadina JE, Hackler L, Ge LJ, Kastin AJ (1997) A potent and selective endogenous agonist for the mu-opiate receptor. Nature 386:499-502.

Zhao ZQ, Duggan AW (1988) Idazoxan blocks the action of noradrenaline but not spinal inhibition from electrical stimulation of the locus coeruleus and nucleus Kolliker-Fuse of the cat. Neuroscience 25:997-1005.

Zhao ZQ (2008) Neural mechanism underlying acupuncture analgesia. Prog Neurobiol 85:355-375.

Zhou Y, Sun YH, Shen JM, Han JS (1993) Increased release of immunoreactive CCK-8 by electroacupuncture and enhancement of electroacupuncture analgesia by CCK-B antagonist in rat spinal cord. Neuropeptides 24:139-144.

Zhu LX, Li CY, Yang B, Ji CF, Li WM (1990) The effect of neonatal capsaicin on acupuncture analgesia. Acupunct Res 15:285-291.

(Received 10 May 2017, Accepted 26 June 2017)

(Available online 3 July 2017) 